Article

\title{
A Model Process of Integrating Context of Local Culture for Pre-Development Stage in the Design of Cultural and Creative Products-Using Macao's Historical Buildings as an Example
}

\author{
Xizhi Zhang ${ }^{1}$ and Kuo-Hsun Wen ${ }^{2, *}$ \\ 1 Design Programme, Faculty of Humanities and Arts, Macau University of Science and Technology, \\ Avenida Wai Long, Taipa 999078, Macao, China; xzzhang@must.edu.mo \\ 2 Design Programme, Macao Polytechnic Institute, School of Arts, Rua Luis Gonzaga Gomes, \\ Macao 999078, China \\ * Correspondence: khwen@ipm.edu.mo; Tel.: +853-68818105
}

Received: 30 June 2020; Accepted: 30 July 2020; Published: 4 August 2020

\begin{abstract}
In the context of the research on local architectural culture of Macao, this paper explores how architecture's cultural elements can be integrated into cultural and creative product design at the pre-development stage. Therefore, local culture can be effectively disseminated through the medium of cultural and creative products. However, in the process of product design, seemingly, designers often rely on their experience as the main way to develop ideas and designs. This approach can fall short in generating sufficient cognition and interpretation between culture and product design, and the product may fail to truly reflect cultural and creative values. This paper focuses on the cultural elements and the designer's cognition in design development of cultural and creative products. It applies theoretical concepts of Kansei engineering theory as the basis, and, combined with the Semantic Differential Method, tries to extract the most powerful product image elements that influence designers for better understanding of the cultural elements in design development. This paper aims to employ scientific methods to enable designers to better develop designs with cultural and creative connotations, thereby improving the success rate of cultural and creative products. It further proposes a model process of image perception to be employed by designers in early design research and the development stage. By enhancing the resonance of cultural elements for cultural and creative products, the model may shorten the perceptual distance between the designer and the local culture, improve the designer's product development efficiency, and increase consumer satisfaction with the design outcome through added cultural and creative value. As such, the model can optimize the design development for cultural and creative products to achieve the public's aesthetic and cultural expectations, as well as for a sustainable design approach.
\end{abstract}

Keywords: local architectural culture; cultural and creative; product design; pre-development stage

\section{Introduction}

Culture —an indispensable part of cultural and creative product design—plays a crucial role in the value addition process of products. Cultural characteristics can be employed by the designer in adding additional value to the product not only benefiting the society's economic growth, but also promoting the uniqueness of local culture to the global market [1]. Therefore, the design of a cultural and creative product is important to understand how to integrate local culture into cultural and creative product design and development. However, the integration of cultural content is not simply a mechanical procedure. Instead, the essence of culture should be integrated into products so that they are accepted 
by users and resonate with them. Such products successfully realize the value of cultural and creative products. The purpose of this study builds on a positioning way for cultural and creative product by digging emotional image based on Kansei Engineering theory. It employs the local architectural culture of Macao as a research source to implement sample testing trying to establish a model process at pre-development stage by excavating an emotional image from local culture. Through analyzing results of a questionnaire survey by Semantic Differential Method, cultural emotional recognition for design development are able to be extracted. As a consequence, the paper suggests a guide for design professionals on how cultural symbols can be extracted rapidly from selected historical buildings for design development in optimizing the design process, as well as to increase design efficiency. At the same time, it could lead to the discovery of the invisible needs of designers to improve the success rate of product design. Eventually, the paper proposes an effective way to assist design professionals by integrating the context of local architectural culture into product design in the pre-development stage. As a result, designers could learn from the study and realize the mapping relationships between cultural elements and emotional images for developing product design with cultural and creative value that product positioning can be achieved rapidly and accurately.

Cultural and creative product design and its research and development $(R \& D)$ can promote the development of the local creative economy that emphasizes the support and promotion of culture and art to the economy [2]. For example, British tin factory manufacturers have changed their design methods through alliances with handicraft designers to increase the value of their products and create new ways of organization [3]. At present, the Macao SAR government is also vigorously promoting the development of creative industries with the bid to diversify its economy and add more economic pillars, in addition to the gaming industry. In 2013, the Cultural Industry Fund was established. Its main purposes are to promote the incubation, industrialization, and scaling of cultural industry projects, explore projects with distinctive local cultural characteristics, and promote the research, design, development, production, marketing, and awareness of cultural and creative commodities [4].

Macao, being an intersection of a multicultural city, has a cultural context that is very complex and diverse in possessing the unique cultural representation of historical buildings. Such representation can be regarded as a development of the collision and fusion from alien cultures which condense heavy cultural value. However, in the process of globalization, homogenization increases, prompting people to realize the importance of their own local culture [5]. Local culture is formed by the accumulation of people's lifestyles over time and it is also a kind of memory and cultural context. In various regions of the world, the relationship between world culture and local culture has come into focus, and individuals have begun to pay more attention to their own society and the social and cultural significance of their own nation, injecting their learnings into product design and development, thus intersecting current culture with products and triggering a memory of the lifestyles of the past [6].

In addition, Macao is one of the major tourist attractions of the world, receiving a large number of tourists every year. On the website of its Bureau of Statistics, it is reported that the number of arrivals in 2018 was 3.58 million [7]. Therefore, it needs a large number of products with local cultural elements for tourists to purchase. At present, not only is there limited variety in Macao's cultural and creative products, but there is also a lack of research on the local cultural attributes of products. The research presented in this paper relates to how cultural and creative products can be promoted by extracting cultural elements in the pre-development stage; that is, through creative design, the local culture of Macao can be integrated into products and disseminated. Thus, tourists who come to Macao can additionally experience Macao's culture through its products, thereby enhancing the added value to products. Accordingly, cultural and creative products have cultural attributes in addition to the core elements of the product. In the future, these attributes can evoke memories about Macao in the owners of the products and support their spiritual sense of belonging and identity. 


\section{Literature Overview}

Every country has its unique cultural identity [8]. In the highly competitive global market, the homogeneity of products is slowly causing them to lose their recognition. Therefore, applying characteristics of cultural image is becoming more important [9]. Nonetheless, it aims at the enhancement of product identity in the global market, or to increase consumption experience of individual customer, features of cultural image are all regarded as the excellent characteristic to improve product design $[3,10,11]$. Culture reflects the true value of design works. A good product design not only has good function and shape, but also elicits ideological sentiments and spiritual inspiration [12]. Leong and Clark considered that knowledge based on culture can provide new ways of thinking and designing [13]. Cultural elements in cultural and creative products generally contain two dimensions. One is the continuation of historical culture. Historical culture is the so-called cultural context and the relationship between one thing and other things in time. It emphasizes the inheritance of culture and can satisfy consumers' memories and thoughts of the past, resulting in spiritual comfort. The other is the inheritance of local culture.

Through cultivating cultural and creative products as a kind of local cultural symbol, it could adapt an aesthetic approach of the current mainstream to be implemented effectively [14]. There are several previous studies relating and representing the above consequence; for example, "Cultural and creative Products Design by employing local culture of Dunhuang in Gansu", "Research and development of cultural and creative products based on the red culture in Jinggangshan", and "The product deployment of native gold in Nanjing area" [15]. These examples are all based on the perspective of local culture extracting their cultural characteristics to carry out the research and development of cultural and creative products. Currently, most of the cultural products which are reachable easily for customers are simply applying cultural elements; for instance, the application of texture and material or copying the form directly as cultural elements. However, being an excellent product, which can impress people truly; it seems that there are missing expressions from other aspects [16]. The key reason can be the lack of a scientific and effective way in the pre-development stage to reveal the cultural and creative value in product design. Hence, the study centers on implementing the research methodology via Kansei Engineering theory and the Semantic Differential Method to guide designers on how to achieve a more effective development for cultural and creative products. At present, Toyota, Samsung, Canon, and other companies all apply Kansei engineering theory to design in the pre-development stage [17]. Nevertheless, as a new discipline in the academic field of product design, Kansei engineering theory has resulted in attention and research application among many countries. In addition, it has been brought into the design and development process of various new products frequently in product design research.

In recent years, many experts engaged in design practice and education have conducted research on the theory and methods of Kansei engineering, which is conducive to the development of new products. Efforts have been made in the fields of daily products, transportation, and color design [18]. Su et al. summarized and analyzed the perceptual cognitive mining involved in Kansei engineering theory to establish a feasible system for product modeling design [19]. Li et al. used the theory of Kansei engineering theory and applied statistical analysis to derive a quantitative relationship between design elements and design style, and determine aspects of emotional appeal in users [20]. Moreover, Yang et al. analyzed the perceptual appeal of the portable water bottle and found a relationship between the perceptual characteristics of the bottle shape and the design elements of the bottle [21].

\section{Local Architectural Culture of Macao}

Several hundred years of historical development has shaped the local culture of Macao and infused with elements of both Eastern and Western cultures. These two cultures together produced Macao's local culture, which is of great historical significance. Geographically, Macao's culture belongs to the Chinese cultural system, but because the area was ruled by the Portuguese for more than 400 years, it has been influenced by Western culture as well. Macao's culture is different from traditional Chinese 
culture, and its cultural connotation is rich and colorful. As stated by Chen, "Macao has Chinese culture, Portuguese culture, religious culture, architectural culture, custom culture, food culture, and festival culture [22]."

The so-called architectural culture is regarded as an important cultural form that intuitively reflects the characteristics of national, cultural, and historical background and regional development [23]. A unique cultural and historical characteristic can be felt from Macao's architectural culture. On less than 20 square kilometers of land, there are various buildings of different styles characteristic of the East and West, such as the Ruins of St. Paul's with the Italian Baroque style of the Renaissance; the Cathedral of Macao and the St. Dominic's Church with Spanish religious characteristics; the Macao SAR Government Headquarters and the Macao Military Club in Portuguese architectural style; Hill Top Hospital in the Gothic architectural style; and the Moorish Barracks. In addition to these European style buildings, there are many Chinese style ancient buildings, such as the A-Ma Temple with a history of 500 years and the Puji Temple, the Pou Tai Un Temple, and the Tam Kung Temple in Coloane. These buildings constitute a seamless architectural and cultural landscape that combines Chinese and Western cultures [22]. As a modern city, Macao derives its charm partially from its architecture. A city is a place where people form and experience collective memories [24]. Accordingly, through exploring meaning of a cultural and creative product, people's memories of Macao may be able to expand from limited to unlimited and from instant to eternal. As a result, memories can take individuals back to the time they spent in Macao. There is no doubt that the memories and the city coexist, and that the city "exists on memory [25]."

Besides, several statistical data show that cultural and creative products can cause people to perceive that the images of their memories are emerging into reality, enabling users to recall moments and perceptions of life. As Kansei engineering is a theory combining human emotions and rational analysis, the study applies its engineering techniques as the method to explore the relationship between human sensibilities and the design characteristics for product design [26]. Subsequently, memories and impressions of a visited place can be produced while using a product purchased from there. Especially when going through a journey with the attempt to understand various cultures and acquire different cultural experiences, memories relating to the place or historical buildings will cause people to recall their past experiences where meaning is generated and kept in mind easily.

The Value of Macao's Architectural Culture

Macao's World Cultural Heritage buildings are mainly located in the old city in the south-central part of the Macao Peninsula, also known as the Historic Center of Macao. It is a historical block connected by 22 Chinese style and Western style buildings, traditional streets, and eight square fronts. Particularly, the block has one of longest histories and largest scales in the world, and it fully reflects the symbiosis and integration of Eastern and Western cultures over 400 years. According to the evaluation of UNESCO, Macao is a city with closely linked part of living habits and culture of its local residents [27]. Noticeably, Macao's World Heritage Site represents an exceptional treasure of cultural heritage and reaches the global level. As a consequence, the cultural value of Macao's Cultural Heritage buildings can be considered a masterpiece of human genius. During a certain period of time or in a cultural region of the world, it reflects human values and expressions interacted and influenced by each other in the development process, especially in the fields of architectural research resulting in immortal art creation, city planning, and landscape design.

Macao's cultural historical buildings contains a unique or at least a rare proof of a cultural tradition or a civilization that has disappeared; it marks a certain history of mankind, a firm type of building, or group of buildings at several important stages; it is a traditional human residence representing a certain culture (or several cultures); and it is directly or indirectly related to major events or life traditions, thoughts or beliefs, and art and literary works of tremendous universal importance [28]. Therefore, designing a product to emphasize its cultural value by considering local cultural characteristics has become a critical issue in the design process [29,30]. In Macao, apparently, 
the most obvious evidence reflecting local culture can those historical buildings which are able to convey the intangible nature [31-33] of messages, as well as the implicit cultural value to make them become tangible and comprehensible through the design of meaningful products.

\section{Research Methods}

Using the theoretical concept of emotional imagery in Kansei engineering theory, this paper carries out a series of design studies. Nagamachi considers that the feelings or images of a person with respect to an objective object resulting from the sensory system and brain consciousness are psychological feelings of an objective thing or a person's emotional embodiment and expected feelings of an objective thing [34]. This study divides the designer's emotional images of a product into different quantified levels through Kansei engineering theory, combined with the analysis of using cultural content of historical buildings to implement questionnaire surveys, interviews, and the subjective measurement Semantic Differential Method. Data was obtained and applied through statistical methods to analyze and derive abstractions that can guide effective extraction of cultural carriers for the design of cultural and creative products.

The purpose of Kansei engineering theory is to establish a certain relationship or mapping between information relating to the qualitative level of abstract changes of human emotions and the "things" that result in human emotions [35]. In recent years, the research focus of Kansei engineering theory has been mainly implemented on the extraction and analysis of human emotional information. As a consequence, emotional images are excavated through the subjective measurement method based on Kansei engineering theory. This kind of abstract emotional information is collected and processed into data, and then the collected data is classified and analyzed to organize a complete emotional information processing system. Thus, it can facilitate effective extraction of emotional information and "things" for designers and provide design guidance as reference [19].

The Semantic Differential (SD) Method is an experimental method created by American psychologist Osgood in 1942. In general, Semantic Differential Method is used for studying the psychological images of a subject. It is a method to read and understand people's cognitive dimensions with respect to a certain thing by digitizing people's abstract emotional images through the help of scientific methods such as experimental statistical calculation [36]. The application of Semantic Differential Method requires the subject to map the meaning of things or concepts on an evaluation scale with a corresponding score. On this basis, the scale of Semantic Differential Method is established. In additions, the SD questionnaire generally consists of three elements [19]; namely, design object, evaluation scale, and subject. The study also refers to these three elements by conducting an experimental investigation and constructing a designer's emotional image scale distribution map for the product in order to help guide the direction of product development. Based on such connotation, the paper designed a questionnaire by digging cultural characteristics from local historical buildings of Macao as the main cognitive goal. According to the interpretation to the result of anticipated questionnaire, the research strives to modify the existing product design process and proposes preliminary research of a model process for design professionals in product design.

\section{Research Process}

Under the research framework based on Kansei engineering theory, this study focuses on the designer's cognition of emotional images where cultural symbols can be extracted by designers when concerning the design development for cultural and creative products. The research involved subjects and representative samples, both of which are selected thoughtfully. By corresponding to individual design experience, a hypothesis was made on university students majored in product design that are assumed as having similar design experience with design professionals. The reason why research subjects were chosen from product design students studying in universities is because of the professional education and training they had. Besides, these students shall be familiar with the $R \& D$ process of the product design and having practical experience of completing product design 
independently through learning experience. In terms of concerning the cognition of product design, their experience in design exploration is reckoned as similar to those design practitioners. According to the hypothesis above, the procedure of selecting the subjects and sample contents of the questionnaire is as follows.

\subsection{Subject Selection}

The subjects to be selected are students majored in product design from the Macau University of Science and Technology. In total, there were 37 subjects, of which 30 were undergraduates and 7 were postgraduate students. They were aged between 23-25 years old and have lived in the city of Macao for at least 4 to 6 years. All of them were assumed to possess enough understanding of the local culture of Macao, the emotional bonds with the city, and a certain perception of urban buildings for the basis of needed conditions of hypothesis to be analogous in having similar design development experience with design related practitioners.

\subsection{Sample Selection}

The paper explored the architectural culture of Macao, and the building forms form historical buildings were used as the research sample [37]. The sample comprised more than 20 historical buildings of Macao in the UNESCO World Heritage Site List of July 15, 2005: A-Ma Temple, Moorish Barracks, Mandarin's House, St. Lawrence's Church, St. Joseph Seminary and Church, Teatro Dom Pedro V, Sir Robert Ho Tung Library, St. Augustine's Church, Civil Affairs Department Building, Sam Kai Vui Kun (Kuan Tai Temple), Holy House of Mercy, Se Cathedral, Lou Kau Mansion, St. Dominic's Church, Ruins of St. Paul's, Na Tcha Temple, Walls of Macao, Monte Fort, St. Anthony's Church, Casa Garden, Old Protestant Cemetery, and Fortaleza da Guia (including Guia Lighthouse and Chapel of Our Lady of Guia) [38]. Among these heritage buildings, 19 three-dimensional historical buildings were selected as the research sample (Table 1). The selection concerns of the sample's image are based on building's historical value, time established, and cultural background for implementing sample analysis [39].

Table 1. Sample images of buildings in the historical area of Macao.

\begin{tabular}{|c|c|c|c|c|}
\hline Ref. & Images & Building & Time & Cultural Background \\
\hline 1 & & A-Ma Temple & 1488 & A-Ma Temple is one of the most existing temples in Macao. \\
\hline 2 & & Moorish Barracks & 1874 & $\begin{array}{l}\text { The camp of the police who came to Macao from India at that time. } \\
\text { The masonry buildings are influenced by Arabian and Gothic architecture. }\end{array}$ \\
\hline 3 & & Mandarin's House & 1869 & $\begin{array}{l}\text { The Zheng Family House now occupies an area of nearly } 4000 \text { meters and } \\
\text { is the largest private residence in Macao. The building has both the } \\
\text { distinctive characteristics of a traditional Guangdong Ming mansion and } \\
\text { the Western architectural characteristics that can be seen everywhere. } \\
\text { It fully embodies the characteristics of Macao's integration of Chinese and } \\
\text { Western cultures. }\end{array}$ \\
\hline 4 & & $\begin{array}{l}\text { St. Joseph's Seminary } \\
\text { and Church }\end{array}$ & 1846 & $\begin{array}{l}\text { Founded in the mid-16th century, St. Lawrence's Church is one of the three } \\
\text { old churches in Macao. }\end{array}$ \\
\hline 5 & & $\begin{array}{l}\text { St. Joseph's Seminary } \\
\text { and Church }\end{array}$ & 1728 & $\begin{array}{l}\text { St. Joseph's Seminary and Church were founded by Jesuits in } 1728 \text { and } \\
\text { trained many talents from churches in China and Southeast Asia. It is a } \\
\text { Baroque architectural style. }\end{array}$ \\
\hline
\end{tabular}


Table 1. Cont.

\begin{tabular}{llll}
\hline Ref. & Building & Time & Cultural Background \\
\hline & & &
\end{tabular}

7

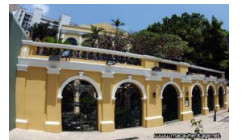

Sir Robert Ho Tung Library

The original owner was Mrs. Carolina Cunha, a villa that came to Macao to 1894 cool off in the summer, and later donated to the Macao government for the use as a library.

The St. Augustine's Church was founded in 1591 by the monks of the
Order of Austin of Spain, and it is the venue for important festivals of the
Macao Catholic Church.

10 Has distinct Southern European architectural styles and features.

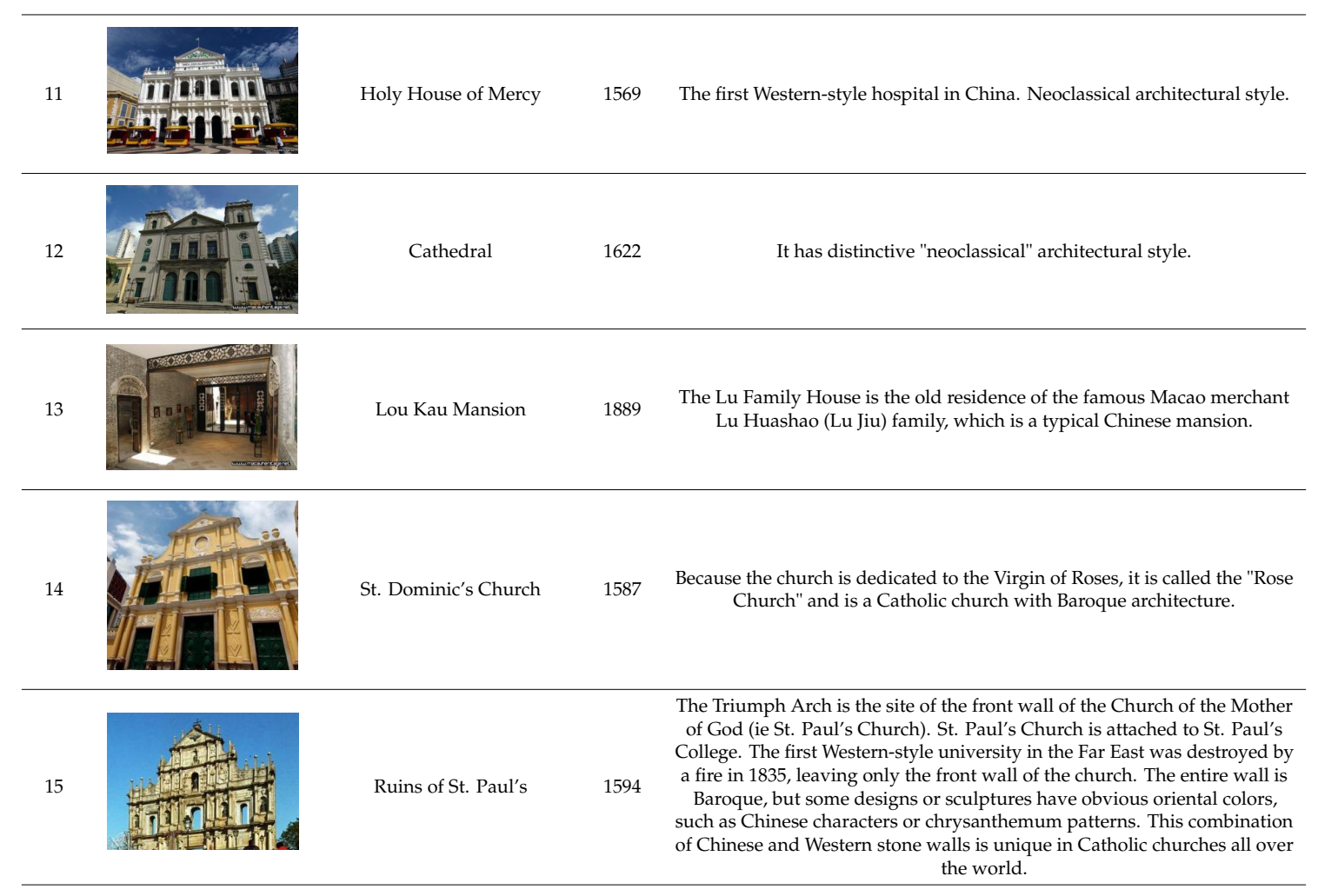

16

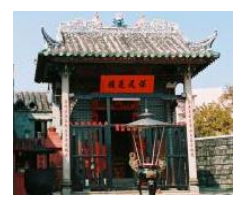

Na Tcha Temple $\quad 1888$

A temple of folk faith with local characteristics of Macao 
Table 1. Cont.

Ref.

\subsection{Questionnaire Content and Design}

In this study, the content of the questionnaire mainly applied information science concepts of Kansei engineering theory to infer thinking in combination with the Semantic Differential Method. After accepting the sample information, the subjects were requested to make inferences along three major emotional factors; namely, emotional motivation, emotional image, and time frequency to perceive the emotional cognition of cultural symbol extraction in the early stage of cultural and creative product design. Within emotional motivation, three emotional factors; namely, memory, cultural communication, and high popularity, were used to study the subject's motivation for selecting the sample as the design carrier. Within the emotional image, three emotional factors; namely, invigorating spirit, happiness, and physical and mental relaxation, were used to test the emotional psychological response when the sample was used as a product design carrier. Finally, three emotional factors of the time dimension; namely, frequent (multiple times within a year), persistent (multiple times within three years), and postponed (multiple times within five years), were used to test the emotional frequency between the subject and the building. The questionnaire was used to quantify the subject's emotional needs hidden in the sample. After statistical evaluation, it was used for qualitative and quantitative research in order to propose a scientific basis for judging the strength of obtaining cultural symbol elements in the design of cultural and creative products.

The questionnaire survey of this study was conducted online. A total of 37 valid questionnaires were obtained. The subjects scored a single sample of emotional cognition scale, in which 1 indicated the lowest emotional cognitive intensity, and 5 indicated the highest emotional cognitive intensity. Before the survey, this study conducted a survey on the mapping relationship between the Macao buildings that represent the local cultural carriers and the emotional factors. The survey descriptions are as follows:

1. Emotional motivation: Emotional motivation in designing the questionnaire is mainly employed for exploring the main consideration of emotional factors which is considered as a driving force during early design phase for a designer. It was also the demand for psychological activities when 19 buildings were selected as design symbols. Emotional memory: It is a memory about an emotion that has been experienced. It is often intertwined with image memory [40]. In designing a cultural product, the memory emotion combines with a certain image symbol to generate corresponding emotional memories, which are consistent with the emotions that the designer wishes to express. Cultural communication: It is the interaction of culture of one society with that of another, from one region to another, and from one group to another [41]. In the study, architecture can be considered as a medium for cultural communication. The building itself is a carrier of information. The cultural connotation conveyed can better reflect the historical cultural 
context and cultural heritage of a city, a region, or even a country. High popularity: This means most of the public shares a perception of the popularity of the building.

2. Emotional image: Emotional image cognition is a process in information processing. After the initial observation of a real thing, the cognition of different emotion images is combined by comparing and thinking of different types of knowledge and experience structures stored in the individual's brain [42]. From the perspective of cognitive psychology, the designer analyzes the emotional expressions embodied in the 19 buildings, such as the three different emotions of invigorating spirit, happiness, and physical and mental relaxation. Invigorating spirit: This means the mood and feeling at the time of visiting the building is very exciting. Happiness: The feeling at the time of visiting the building is a very happy feeling. Physical and mental relaxation: The feeling at the time of visiting the building is relaxing both physically and mentally.

3. Time dimension: In the questionnaire used in this study, the time dimension test was mainly based on the concept of place attachment developed in location theory (geography) and attachment theory (psychology). It has always been valued by scholars in the fields of human geography, environmental psychology, and recreation. Tuan was the first to combine these two theories make "the emotional connection between people and places or environments [43]." This is also the source of the concept of sense of location. Later, Williams and Roggenbuck first proposed the concept of place attachment, that is, an individual's sense of belonging to a special place [44]. The study mainly conducted the frequency test in time based on the designer's emotional connection with the 19 buildings:

- Frequent (multiple visits within 1 year): The subject planned to visit the building multiple times a year;

- Persistent (visit again within 3 years): The subject planned to visit the building multiple times within three years;

- Postponed (visit again within 5 years): The subject planned to visit the building multiple times in five years.

The questionnaire was created based on the results of the questionnaire survey (see Table 2). The representative samples were combined with the emotional cognitive factors that affect the designer to obtain the SD questionnaire, statistically analyze the results, obtain the designer's emotional cognitive scale evaluation table, and mine the designers' emotional perceptions of the sample. This process was conducive to the extraction of elements of cultural and creative product design. This study explored the designer's cognition of the emotional images of cultural extraction in cultural and creative products within the framework of Kansei engineering theory. The research process is shown in Figure 1.

Table 2. SD questionnaire survey on buildings in Macao.

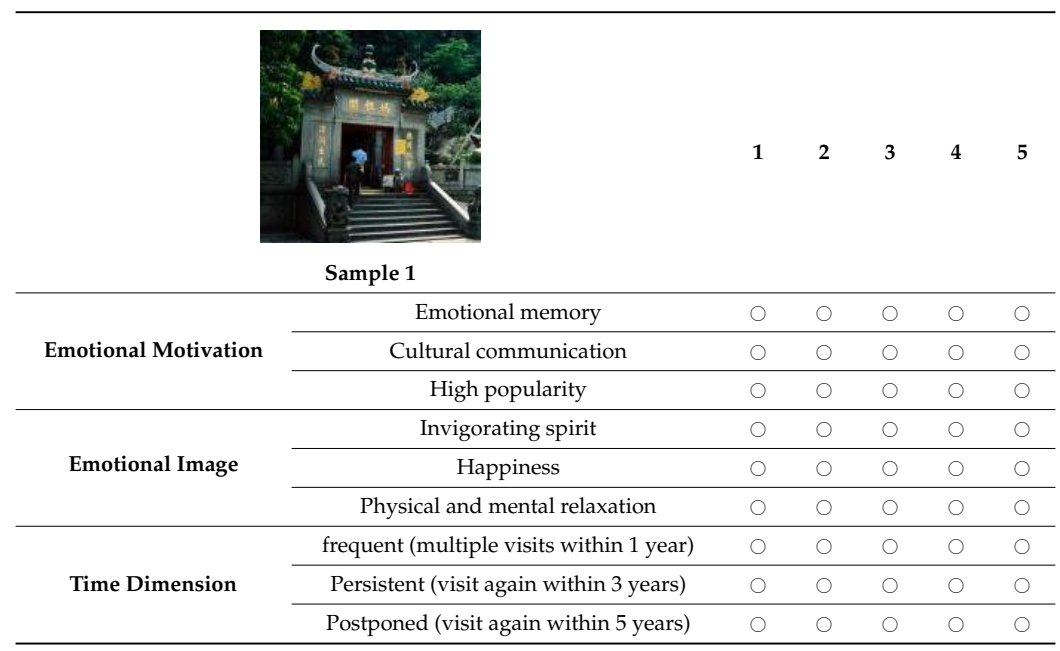




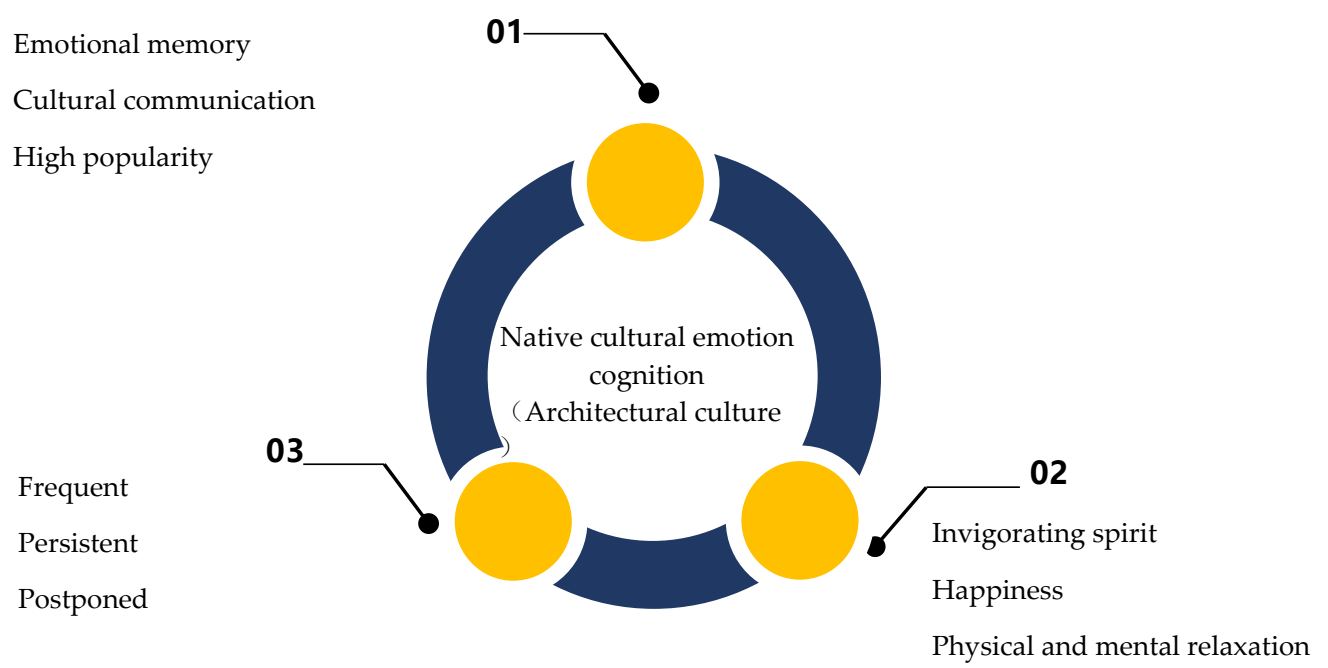

Figure 1. Process to analyze the native cultural emotion cognition.

\subsection{Data Analysis}

In the design of the questionnaire, the Semantic Differential Method was applied. On the basis of the designer's perceptions of the sample and through the measurement of the building's emotional cognition, the data was used to mine the designer's appeal to emotional images. This study combined three groups of perceptual image vocabulary of different types and 19 representative samples of buildings in Macao to create an SD questionnaire, as shown in Table 2. Valid questionnaire surveys of 37 people were obtained through the survey method of online filling of the questionnaires. The data from the subjects was collected, and the average value of emotional cognitive evaluation was calculated using Equation (1), where i represents the number of samples, $j$ represents the classification of emotional cognitive factors, and $\mathrm{k}$ represents the number of subjects.

$$
\bar{A}_{i j}=\frac{\sum_{k=1}^{K} A_{i j}^{k}}{K}
$$

The average value of the $j$ th emotional cognition of any $i$ th sample of all subjects can thus be obtained. The data is shown in Table 3. 
Table 3. Evaluation form of subject's emotional cognition.

\begin{tabular}{|c|c|c|c|c|c|c|c|c|c|}
\hline \multirow{2}{*}{ Sample } & \multicolumn{3}{|c|}{ Emotional Motivation } & \multicolumn{3}{|c|}{ Emotional Image } & \multicolumn{3}{|c|}{ Time Dimension } \\
\hline & Emotional Memory & Cultural Communication & High Popularity & Happiness & Invigorating Spirit & Physical and Mental Relaxation & Frequent & Persistent & Postponed \\
\hline Sample1 & 3.73 & 4.16 & 4.27 & 3.38 & 3.19 & 3.30 & 2.35 & 2.76 & 2.46 \\
\hline Sample2 & 3 & 3.19 & 2.95 & 3.03 & 2.95 & 2.97 & 2.03 & 2.08 & 2.22 \\
\hline Sample3 & 3.78 & 4.16 & 4 & 3.62 & 3.24 & 3.43 & 2.57 & 2.41 & 2.57 \\
\hline Sample4 & 3.38 & 3.51 & 3.32 & 3 & 3.08 & 3.27 & 2.51 & 2.24 & 2.22 \\
\hline Sample5 & 3.57 & 3.87 & 3.62 & 3.27 & 3.24 & 3.30 & 2.73 & 2.32 & 2.43 \\
\hline Sample6 & 3.76 & 3.89 & 3.84 & 3.68 & 3.43 & 3.62 & 2.84 & 2.57 & 2.78 \\
\hline Sample7 & 3.35 & 3.78 & 3.41 & 3.41 & 3.22 & 3.38 & 2.65 & 2.76 & 2.65 \\
\hline Sample8 & 3.03 & 3.30 & 2.97 & 3.03 & 2.89 & 3.05 & 2.16 & 2.35 & 2.30 \\
\hline Sample9 & 3.81 & 3.95 & 4.03 & 3.54 & 3.32 & 3.16 & 2.84 & 2.76 & 2.60 \\
\hline Sample10 & 3.24 & 3.43 & 3.03 & 3 & 3.05 & 2.84 & 2.19 & 2.11 & 2.22 \\
\hline Sample11 & 3.22 & 3.19 & 3.16 & 3.08 & 3.03 & 3 & 2.30 & 2.19 & 2.43 \\
\hline Sample12 & 3.16 & 3.24 & 3.32 & 2.95 & 2.92 & 2.97 & 2.30 & 2.27 & 2.35 \\
\hline Sample13 & 3.57 & 3.68 & 3.68 & 3.54 & 3.22 & 3.19 & 2.46 & 2.32 & 2.35 \\
\hline Sample14 & 3.89 & 3.84 & 3.92 & 3.62 & 3.35 & 3.35 & 3 & 2.87 & 2.81 \\
\hline Sample15 & 4.57 & 4.76 & 4.78 & 4.14 & 4.11 & 4.03 & 3.84 & 3.73 & 3.81 \\
\hline Sample16 & 3.65 & 3.81 & 3.87 & 3.57 & 3.51 & 3.22 & 2.81 & 2.60 & 2.49 \\
\hline Sample17 & 3.32 & 3.32 & 3.32 & 3.14 & 3.14 & 2.76 & 2.30 & 2.19 & 2.38 \\
\hline Sample18 & 3 & 3.11 & 3.03 & 2.97 & 2.95 & 2.87 & 2.11 & 2.08 & 2.16 \\
\hline Sample19 & 3.97 & 4.05 & 4.27 & 3.81 & 3.60 & 3.43 & 2.97 & 2.84 & 2.78 \\
\hline
\end{tabular}


The comparison chart of the average value of each building is shown in Table 4 .

Table 4. Comparison diagram of average values of buildings.

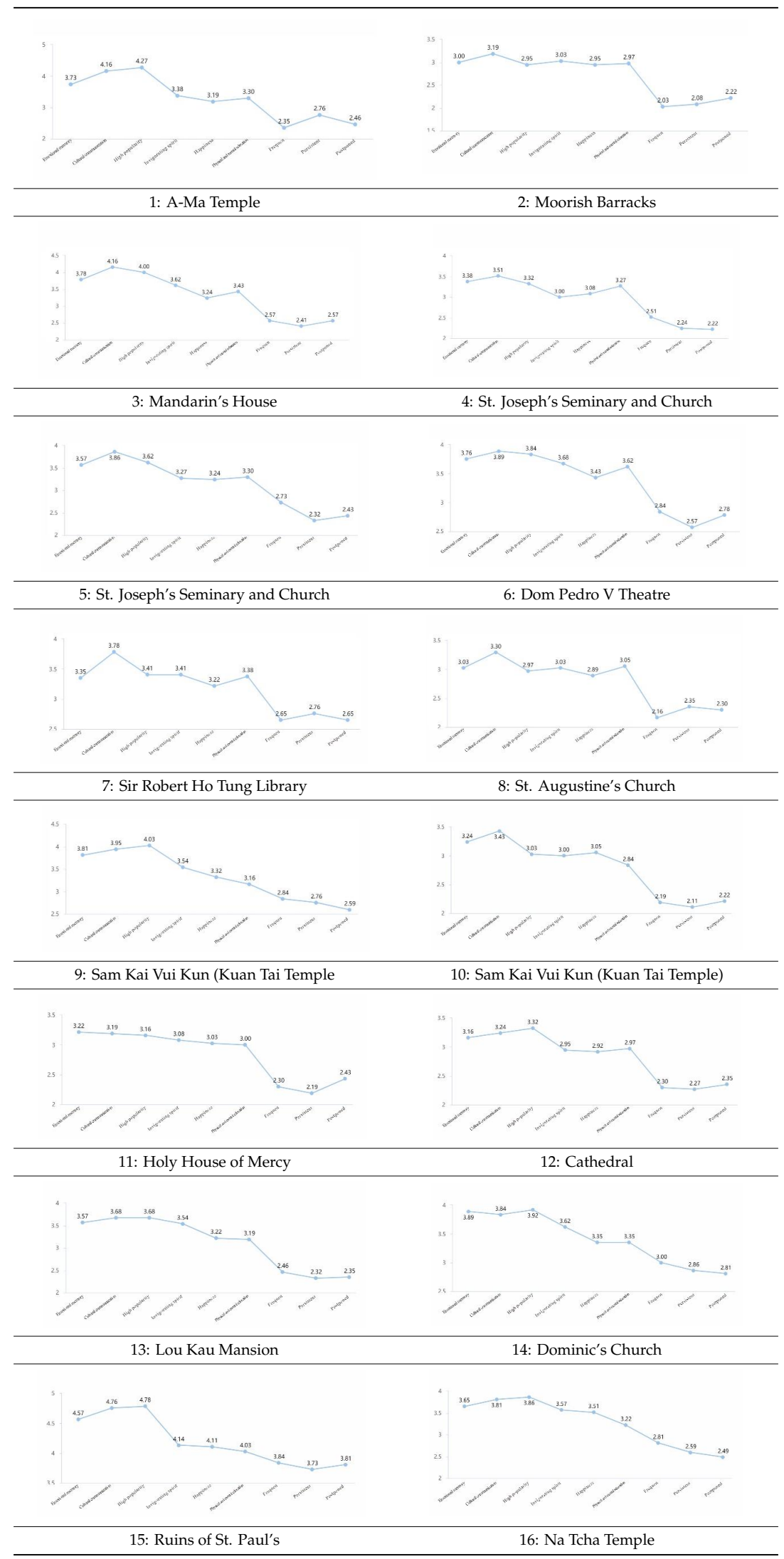


Table 4. Cont.

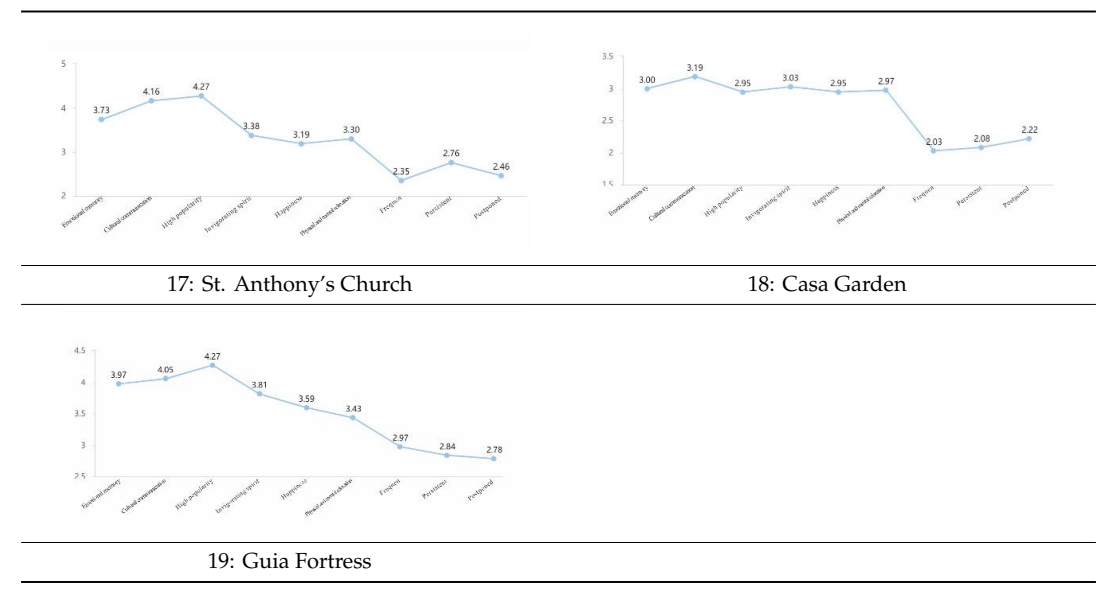

\section{Discussion}

To those research samples selected from World Heritage Architecture of Macao, description and analysis of them include the building's historical value, time established, and culture background. The target survey respondents are 37 majored in product design at Macau University of Science and Technology. The hypothesis of this study takes target respondents to represent design majored students and designers both having similar design knowledge on recognizing local culture and emotional appeals, as well as deep perception of historical buildings. Apart from owning professional knowledge in product design, these survey respondents were reckoned as those who possess comparable experience of design exploration at the pre-development stage and can complete design work independently. In addition, the creating of implementable process in digging emotional recognition of local culture is mostly through three emotional factors. They are "Emotional Motivation (memory, cultural communication, high reputation), "Emotional Images (excitement, happiness, relaxation)", "Time Dimension (frequency, continuity, extension)". Through implementing the proposed questionnaire, the hidden emotional needs of respondents are quantified in achieving the purpose of emotional recognition among respondents and selected historical buildings. Consequently, it reaches the judging evaluation of applying cultural symbols to attain the adequate outcome for the design development of cultural and creative products.

Based on analysis of the results, when designers are designing cultural and creative products, they need to consider the emotional cognition when extracting the cultural symbols. This study found the mapping relationship between representative samples and emotional factors. According to the analysis of the data collected from Sample 1 by appraising three major emotional factors, the average value of memory in the emotional motivation was 3.73 , the average value of cultural communication was 4.16 , the average value of popularity was 4.27 , the average value of happiness to emotional image was 3.38 , the average value of invigorating spirit was 3.19, the average value of physical and mental relaxation was 3.30, the average value of frequent in the time dimension was 2.35 , the average value of persistent was 2.76, and the average value of postponed was 2.46. The trend of the curve of the average value comparison chart was from high to low. The study demonstrates that of the three major emotional factors in the tested sample, for the respondents (designers), the factor with the greatest influence was the emotional motivation, and the smallest was the time dimension (emotional motivation $>$ emotional image $>$ time dimension). In the analysis of 18 other samples, the trend of the curve presented of the average comparison chart was also from high to low, indicating that the respondents (designers) gave much more consideration to the emotional motivation and emotional image when implementing cultural and creative product design than the time dimension. 
This study used Equation (2) and the average of the $j$ th emotional cognition of the $i$ th sample to obtain the average value of the emotional intensity of 19 samples, as shown in the following Table 5.

$$
\bar{A}_{i}=\frac{\sum_{j=1}^{M} \bar{A}_{i j}}{M}
$$

Table 5. Evaluation table of emotional cognitive intensity of subjects.

\begin{tabular}{cccccc}
\hline $\begin{array}{c}\text { Sample } \\
\text { Number }\end{array}$ & $\begin{array}{c}\text { Emotional } \\
\text { Intensity }\end{array}$ & $\begin{array}{c}\text { Sample } \\
\text { Number }\end{array}$ & $\begin{array}{c}\text { Emotional } \\
\text { Intensity }\end{array}$ & $\begin{array}{c}\text { Sample } \\
\text { Number }\end{array}$ & $\begin{array}{c}\text { Emotional } \\
\text { Intensity }\end{array}$ \\
\hline 1 & 3.3 & 8 & 2.8 & 15 & 4.2 \\
\hline 2 & 2.7 & 9 & 3.3 & 16 & 3.3 \\
\hline 3 & 3.2 & 10 & 2.8 & 17 & 2.9 \\
\hline 4 & 3.0 & 11 & 2.9 & 18 & 2.7 \\
\hline 5 & 3.1 & 12 & 2.8 & 19 & 3.5 \\
\hline 6 & 3.4 & 13 & 3.1 & & \\
\hline 7 & 3.2 & 14 & 3.4 & & \\
\hline
\end{tabular}

The above result indicates that in the 19 samples, the first six samples with greater emotional intensity are as follows: the average value of Sample 15 was 4.2, the average value of Sample 19 was 3.5, the average value of Sample 6 was 3.4, and the average values of Samples 1, 9, and 16 were 3.3. As a result, it is noticeable that in Macao's local culture, historical buildings can be employed as the cultural symbol to assist design development for cultural and creative products according to the application through using the extracted cultural characteristics from the building form and facade. That is, designers need to first sort out the interdependent and interactive relationships between the culture and product. In accordance with the result above, it is perceivable that culture can resemble owning actual form and symbolic meaning to a specific product [45].

Consequently, this study concludes that the form of Macao's historical architecture can be used as the source to extract cultural characteristics and be integrated into the design of cultural and creative products carrying certain symbolic meanings of Macao. Among them, the average emotional intensity of the six buildings of Ruins of St. Paul's, Fortaleza da Guia, Teatro Dom Pedro V, A-Ma Temple, Civil Affairs Department Building, and Na Tcha Temple were $\geq 3.3$, whereas the average value of the emotional intensity of Ruins of St. Paul's was 4.2, ranking highest in the 19 buildings. From the results, it can further conclude that when designers design cultural and creative products with Macao's cultural connotations, the above six buildings that reflect the most local cultural elements of Macao are the main candidates to choose from.

\section{Conclusions}

The key concern of this research centers on how to effectively extract cultural symbols in the design process of product design to enhance the cultural value of cultural and creative products. Employing Kansei Engineering theory and combined with the Semantic Differential Method, research divided the perception images of local culture into three major emotional factors. By using 19 historical buildings as research samples and applying the analyzed result of the questionnaire, designers' perception images of local culture are able to be excavated in obtaining the evaluation of image scale. This study analyzed and summarized the mapping relationship between buildings and emotional images of cultural elements as supportive data for the design of a cultural creative product. As a result, the study suggests a model process in the pre-development stage as a reference for the recognition of subsequent cultural elements of cultural and creative products. 
However, there remains modifiable possibility to improve research results. Firstly, due to time concern, respondents of the questionnaire survey are students majored in product design. Although the research subjects have undergone professional education and training, such experience may not be the same as what designers possess and may have caused certain limitations to be placed on the research results. Besides, standing on the perspective to achieve an appropriate design outcome, end-user's perception of emotional cognitive intensity to the specific cultural characteristics of Macao is also very crucial and a possible way to improve the research result. Therefore, it would be better for the questionnaire survey to include respondents such as Macao residents and tourists. Together with the analyzed result from university students majored in product design, it is helpful to designers as well in pre-development while implementing design development for product designs in particular to the attempt of applying cultural elements. As a consequence, future research and design of the questionnaire survey should include not only the consideration of experienced design practitioners, residents, and tourists as the respondents (subjects), but also with in-depth questions relating to how visitors read the building and such recognition to be interpreted as sort of cultural characteristics for designers. This approach will certainly improve the accuracy and referencing value of the results. Secondly, in terms of selecting representative samples, apart from those historical architecture mentioned previously, there may exist other buildings in Macao that are with cultural connotations too. That is, cultural characteristics can also be extracted from these buildings. As a result, future research needs to be extended by including buildings with cultural connotations to achieve a better outcome.

Applying Kansei engineering together with three emotional factors of emotional motivation, emotional cognition, and time dimension, this study finds that the most influential factor for designers is to consider the effectiveness of extracting cultural symbols. From the analyzed result, it shows that the highest influential intensity of emotional motivation for designers is the emotional motivation, followed by the emotional cognition, and the influence of time dimension shown relatively low. In terms of the impact on perception intensity and the total concern to analyze the background deeply, as well as the reason caused, suggestions of this study are appropriate for the research in an early stage of design development, and the reference and application of extracting cultural connotation.

Finally, cultural and creative products are reckoned as the necessary route of production to implement cultural communication for a place. The richness and diversity of a product is an embodiment of local multiculturalization. Thus, the design development needs to inspire design thinking continuously, explore product research constantly, and discover the local cultural characteristic deeply together with the method of theory and practice in creating a sustainable path for the design of cultural and creative products.

Author Contributions: Conceptualization, X.Z. and K.-H.W.; methodology, X.Z. and K.-H.W.; software, X.Z.; validation, X.Z. and K.-H.W.; formal analysis, X.Z. and K.-H.W.; investigation, X.Z.; resources, X.Z.; data curation, X.Z.; writing—original draft preparation, X.Z.; writing—review and editing, K.-H.W.; visualization, X.Z.; supervision, K.-H.W.; project administration, X.Z.; funding acquisition, X.Z. All authors have read and agreed to the published version of the manuscript.

Funding: This research was funded by MACAU UNIVERSITY OF SCIENCE AND TECHNOLOGY FOUNDATION, grant number FRG-19-022-FA

Acknowledgments: The authors are extremely grateful for the Sustainability journal editorial team's valuable comments on improving the quality of this article.

Conflicts of Interest: The authors declare no conflict of interest.

\section{References}

1. Lin, R.T. Transforming Taiwan aboriginal cultural features into modern product design: A case study of a cross-cultural product design model. Int. J. Des. 2007, 1, 45-53.

2. Wang, H.; Cao, J. Theoretical and Practical Exploration of the Development of Cultural and Creative Industries; Shanghai Academy of Social Sciences Press: Shanghai, China, 2018; p. 9. 
3. Yair, K.; Press, M.; Tomes, A. Crafting competitive advantage: Crafts knowledge as a strategic resource. Des. Stud. 2001, 22, 377-394. [CrossRef]

4. Xiang, Y.; Cui, S. Regional Synergy and Platform Innovation. In Macao Research Report 2015; Social Sciences Academic Press: Beijing, China, 2015; p. 128.

5. Femandes, T. Global interface design. In Proceedings of the Conference Companion on Human Factors in Computing Systems, Boston, MA, USA, 24-28 April 1994; pp. 373-374.

6. Pi, Y.; Qin, T.; Zhou, Z. Interpretation and Appreciation of Cultural and Creative Products; Southwest University Press: Chongqing, China, 2014; pp. 1-22.

7. Government of Macao Special Administrative Region Statistics and Census Service. Available online: https://www.dsec.gov.mo/zh-MO/ (accessed on 21 July 2020).

8. Hsu, C.H.; Lin, C.L.; Lin, R. A Study of framework and process development for cultural product design. In Proceedings of the International Conference on Internationalization, Design and Global Development, Orlando, FL, USA, 9-14 July 2011; pp. 55-64.

9. Moalosi, R.; Popovic, V.; Hickling-Hudson, A. Culture-orientated product design. Int. J. Technol. Des. Educ. 2010, 20, 175-190. [CrossRef]

10. Handa, R. Against arbitrariness: Architectural signification in the age of globalization. Des. Stud. 1999, 20, 363-380. [CrossRef]

11. Yair, K.; Tomes, A.; Press, M. Design through making: Crafts knowledge as facilitator to collaborative new product development. Des. Stud. 1999, 20, 495-515. [CrossRef]

12. Sun, D. Chinese Traditional Culture and Contemporary Design; Social Sciences Academic Press: Beijing, China, $2015 ;$ p. 42.

13. Leong, D.; Clark, H. Culture-based knowledge towards new design thinking and practice-A dialogue. Des. Issues 2003, 19, 48-58. [CrossRef]

14. Li, J. The Traditional New Life of Guizhou Miao Totem in Cultural and Creative Products. Guizhou Ethn. Stud. 2019, 40, 76-79.

15. Wu, Y. Research on the Development of Cultural and Creative Products Based on Dunhuang Mu-rals; Lanzhou University: Lanzhou, China, 2019.

16. Hsu, C.H.; Chen, R.; Lin, R. Analysis of Application of Digital Archives to Value-Added Design in Cultural Creative Products. In Proceedings of the International Conference on Cross-Cultural Design, Heraklion, Crete, Greece, 22-27 June 2014; Springer International Publishing: Cham, Switzerland, 2014; pp. 731-742.

17. Akira, H. Research strategy of Kansei Engineering. In Proceedings of the Tsinghua International Design Management; Art and science research center of Tsinghua University: Beijing, China, 2002; pp. 1-11.

18. Luo, S.; Pan, Y. Perceptual image theory in product design. Research progress of technology and Application. J. Mech. Eng. 2007, 43, 8-13. [CrossRef]

19. Su, J.; Wang, P.; Zhan, S. Research Progress on key technology of product image modeling design. Mach. Des. 2013, 30, 97-100.

20. Li, J.; Xu, B.; Dong, S. Interior environment design of high speed train based on perceptual Engineering. J. Mach. Des. Res. 2013, 29, 47-54.

21. Yang, Q.; Nie, G.; Yang, Z. Research on the shape of portable kettle based on the theory of joint engineering. J. Donghua Univ. Natl. Sci. 2010, 36, 438-442.

22. Tang, K. A brief analysis of the cultural connotation of Macao. J. Guangxi Univ. Natl. (Philos. Soc. Sci. Ed.) 1996, 66-68.

23. Li, X. Analysis of the relationship between architectural design style and architectural culture. J. Build. Mater. Dev. Dir. 2019, 017(007), 166.

24. Rossi, A. The Architecture of the City; MIT Press: Cambridge, UK, 1982; p. 130.

25. Mumford, L. The City in History: Its Origins, its Transformations and its Prospects; Ni, W.; Song, J., Translators; China Architecture \& Building Press: Beijing, China, 1989; p. 75.

26. Su, J.; Jiang, P.; Zhu, B. Research on equal sensitive work and its application in product design. J. Xi'an Jiaotong Univ. 2004, 1, 60-63.

27. Wang, X.; Liu, J.; He, W. A study on the relationship among tourism motivation, perceived value and destination loyalty: A case study of Macao Cultural Heritage Tourism. Stud. Hong Kong Macao 2015, 2, $23-28$.

28. Macao World Heritage. Available online: http://www.wh.mo/gb/about/ (accessed on 21 July 2020). 
29. Wu, T.Y.; Cheng, H.; Lin, R.T. A study of cultural interface in the Taiwan aboriginal twin-cup. In Proceedings of the 11th International Conference on Human-Computer Interaction, [CD ROM], Las Vegas, NV, USA, 22-27 July 2005; Salvendy, G., Ed.; Lawrence Erlbaum Associates: Mahwah, NJ, USA, 2005.

30. Wu, T.Y.; Hsu, C.H.; Lin, R.T. A study of Taiwan aboriginal culture on product design. In Proceedings of the Design Research Society International Conference-Futureground (Paper No.238) City, Melbourne, Australia, 17-21 November 2004; Redmond, J., Durling, D., de Bono, A., Eds.; Monash University: Melbourne, Australia, 2004.

31. Bortolotto, C. (Ed.) II Patrimonio Immateriale Secondo L'Unesco: Analisi e Prospettive (The Immaterial Heritage According the Unesco: Analysis and Perspective), 1st ed.; Istituto Poligrafico e Zecca dello Stato: Rome, Italy, 2008; ISBN 9788824011464.

32. The Convention for Safeguarding of the Intangible Cultural Heritage. Document Approved at the 32nd Session of the General Conference in Paris on 17 October 2003 and Ratified by Italy on 27 September 2007. Available online: https://ich.unesco.org/en/convention (accessed on 26 January 2018).

33. Kirshenblatt-Gimblett, B. Intangible heritage as metacultural production. Mus. Int. 2004, 56, 52-64. [CrossRef]

34. Fan, Y. Research on Product Image Modeling Design System Based on Kansei Engineering and Neural Network; Lanzhou University of Technology: Lanzhou, China, 2011; pp. 60-70.

35. Li, Y.; Wang, Z.; Xu, N. Kansei Engineering; China Ocean Press: Beijing, China, 2009; pp. 80-100.

36. Llinares, C.; Page, A.F. Differential semantics as Kansei Engineering tool for analyzing the emotional impressions which determine the choice of neighborhood: The case of Valencia, Spain. Landsc. Urban Plan. 2008, 87, 247-257. [CrossRef]

37. Zhang, W.; Jiang, Y.; Xi, S.; He, X.; Zhang, H.; Li, X.; Wu, C. Research on the standardization of cultural elements based on virtual reality. Inf. Technol. Stand. 2017, 3, 59-72.

38. Zhu, R. Research on the Protection and Management of Macao's World Cultural Heritage; Social sciences Academic Press: Beijing, China, 2015.

39. Macao World Heritage. Available online: http://www.wh.mo/gb/site/ (accessed on 15 July 2020).

40. Tao, Z. (Ed.) A Grand Dictionary of Writing; Grand Chinese Dictionary Press: Shanghai, China, $1992 ;$ p. 47.

41. Zheng, J. Educational Culture; People's Education Press: Beijing, China, 2000; pp. 101-103.

42. Zhou, L.; He, Y.; Wang, J. A review of affective analysis. J. Comput. Appl. 2008, 28, 2725-2728.

43. Tuan, Y.F. Topophilia: A Study of Environmental Perception, Attitudes, and Wlues; Prentice-Hall Inc.: Englewood Cliffc, NJ, USA, 1974; p. 126.

44. Williams, D.R.; Roggenbuck, J.W. Measuring Place Attachment: Some Preliminary Results. In Proceedings of the National Parks and Recreation, Leisure Research Symposium, San Antonio, TX, USA, 20-22 October 1989.

45. Krippendorff, K.; Butter, R. Product Semantics-Exploring the Symbolic Qualities of Form. Innovation 1984, $3,21$.

(C) 2020 by the authors. Licensee MDPI, Basel, Switzerland. This article is an open access article distributed under the terms and conditions of the Creative Commons Attribution (CC BY) license (http://creativecommons.org/licenses/by/4.0/). 